\title{
REASONS FOR REFUSALS DURING POLIO VACCINATION CAMPAIGNS IN POSH AREAS OF LAHORE
}

\author{
JUNAID RASHID ${ }^{1}$, KHALID WAHEED ${ }^{2}$ \\ ${ }^{l}$ Deputy District Health Officer (DDHO), Cantt Zone, Lahore \\ ${ }^{2}$ Department of Pulmonology \& Sleep Medicine, Postgraduate Medical institute/Ameer-u-din Medical \\ College/Lahore General Hospital Lahore.
}

How to cite this article: Rashid J, Waheed K. Covid-19: Reasons for refusals during polio vaccination campaigns in posh areas of Lahore. Pak Postgrad Med J 2020;30(3): 90

This is an Open Access article distributed under the terms of the Creative Commons Attribution License (http://creativecommons.org/licenses/by/3.0), which permits unrestricted use, distribution, and reproduction in any medium, provided the original work is properly cited.

One of the main challenges faced during polio campaigns in Pakistan is to tackle the refusals during campaign days. A lot of people are observed refusing oral polio vaccination (OPV) of their children ${ }^{1}$. I worked in eight different campaigns during my duties as deputy district health officer in Cantt. zone Lahore. As Cantt. Zone Lahore has the posh area i.e. Defence Housing Authority (DHA), Cavalry Ground, and Army Cantt Area, so I will mention the reasons for these refusals according to these posh areas.

1- Frequent polio campaigns are the prime concern shown by the parents. They frequently ask why Govt. is so much concerned about these campaigns and that why these are happening frequently. They usually ask our teams to go and vaccinate the poor children in slum areas.

2- Most of the parents in these posh areas are familiar with the concept of routine vaccination. They get their children vaccinated from different tertiary-care hospitals, private hospitals, and some private clinicians (pediatricians). When a team visits during polio campaign days, they simply refuse with the comments that they have already got their vaccinated and that another dose of vaccine may cause serious side effects due to overdosage. Some parents say we will not get our children vaccinated till the approval from our pediatrician.

3- A small proportion of people do not their children vaccinated from the polio teams due to their outer appearances (as most of the members working in the polio campaign belong to poor families).
4- Few parents refuse because in any previous campaign one of their family children suffered from some adverse reaction after polio vaccination ${ }^{2}$.

5- Some parents say they do not trust vaccines being administered in Pakistan. They usually vaccinate their children from foreign countries. This also includes the foreign people residing in these posh areas.

6- Refusals due to religious issues were noticed little as compared to other areas ${ }^{3}$.

In any polio campaign, my biggest apprehension was to tackle this kind of refusals. Luckily, we had a strong team including the assistant commissioner, police, administration, and security offices of these posh areas and social mobilizers who work extremely hard to cover these refusals and achieve excellent results.

\section{REFERENCES:}

1- Hussain SF, Boyle P, Patel P, Sullivan R. Eradicating polio in Pakistan: an analysis of the challenges and solutions to this security and health issue. Globalization Health. 2016 Dec;12(1):63.

2- Naeem M, Adil M, Abbas SH, Khan MZ, Naz SM, Khan A, Khan MU. Coverage and causes of missed oral polio vaccine in urban and rural areas of Peshawar. J Ayub Med Coll, Abbottabad. 2011 Dec 1;23(4):98-102.

3- Khan SA, Ashfaq M, Ayub A, Jamil A, Badshah J, Ullah I, Shahabuddin AS, Khalid F. Developing a three-dimensional narrative to counter polio vaccine refusal in Charsadda. J. Glob. Health. 2020 Dec;10(2). 